\title{
Correction to: Cost-Effectiveness of Parent-Child Interaction Therapy in Clinics versus Homes: Client, Provider, Administrator, and Overall Perspectives
}

\section{Alexis N. French ${ }^{1} \cdot$ Brian T. Yates ${ }^{1} \cdot$ Timothy R. Fowles $^{2}$}

Published online: 20 February 2021

( ) Springer Science+Business Media, LLC, part of Springer Nature 2021

Correction to: Journal of Child and Family Studies https://doi.org/10.1007/s10826-018-1159-4

The original version of this article unfortunately contained a mistake. The Author contributions section currently states:

"A.F.: designed and conducted data analyses for this study, supervised by B.Y. with input by T.F. A.F. and T.F. assisted B.Y. in writing and revising the manuscript."

The original article can be found online at https://doi.org/10.1007/ s10826-018-1159-4.

Brian T. Yates

brian.yates@mac.com

1 Department of Psychology, American University, 4400 Massachusetts Avenue NW, Washington, DC 20016-8062, USA

2 Department of Psychological and Brain Sciences, University of Delaware, Newark, DC, USA
In fact, B.Y. and T.F. assisted A.F. in writing and revising the manuscript.

Although T.F. and B.Y. were both involved in the writing, primary credit should go to A.F. (Alexis French, the first author).

The authorship order above is accurate. 